\title{
VIOLÊNCIA DOMÉSTICA: A Aplicabilidade e Eficácia das Medidas Protetivas como instrumento de prevenção e combate à reincidência na Comarca de Barra do Garças - MT
}

\author{
Claudivina Campos Vasconcelos \\ Pós-graduada em História e Literatura Matogrossense \\ e graduada em Letras pela UFMT. Acadêmica do curso \\ de Direito. Integrante do Núcleo de Iniciação à Pesquisa \\ na linha de Direitos Humanos da Faculdade de Ciências \\ Jurídicas e Sociais Aplicadas do Araguaia (Facisa). \\ claudiavasconcelos2014@outlook.com
}

\section{Gisele Silva Lira de Resende}

Doutora em Educação, com Pós-Doutorado em Educação e Saúde (UFMT). Bacharel em Serviço Social e licenciada em Pedagogia. Professora do Programa de Pós-Graduação em Direito e em Educação da Faculdade de Ciências Jurídicas e Sociais Aplicadas do Araguaia. Professora nos cursos de Direito e de Pedagogia. Professora Pesquisadora do Núcleo de Iniciação Científica na linha Direitos Humanos e Cidadania da Facisa. giselelira@hotmail.com

\section{Resumo:}

Esta pesquisa objetiva analisar a aplicabilidade e eficácia das Medidas Protetivas de Urgência como instrumento de prevenção e combate à reincidência, na Comarca de Barra do Garças-MT. Baseou-se em pesquisas bibliográficas e de campo realizadas na Delegacia Especializada de Defesa da Mulher de Barra do Garças-MT, por meio de análise de inquéritos policiais, instaurados no período entre 2013 e 2015 . Os dados obtidos são contrapostos às medidas adotadas nesta Comarca, como a Rede de Enfrentamento à Violência Doméstica Contra a Mulher, com o intuito de conferir sua efetividade, permitindo evidenciar que apesar de avanços socioculturais e jurídicos conquistados pela mulher ao longo da História, esta ainda vive sob os resquícios de um modelo machista. As medidas existentes oferecem novos caminhos que podem auxiliar na mudança de comportamento do agressor, bem como descontruir uma cultura machista, porém são ainda muito recentes.

Palavras-chave:

Violência contra a mulher. Medidas Protetivas. Reincidência. 


\title{
DOMESTIC VIOLENCE: THE APPLICABILITY AND EFFECTIVENESS OF PROTECTION MEASURES AS APREVENTION INSTRUMENT AND COMBATING RECIDIVISM IN THE COMARCA OF BARRA DO GARÇAS - MT
}

\begin{abstract}
:
This research proposes to verify the applicability and effectiveness of Urgent Protective Measures, as a means of preventing and combating recidivism in judicial district of Barra do Garças-MT. It was based on bibliographic and field research conducted in the Police Station Woman's Defense Specialized of Barra do Garças- MT, through analysis of police investigations, initiated in the period 2013-2015. The data obtained are opposed to the measures adopted in this judicial district such as Line Confronting Domestic Violence Against Women, in order to check its effectiveness. Allowing evidence that despite advances social cultural and legal partner conquered by women throughout history, this also lives in the remnants of a machista model. The existing measures offer new ways that can help in the change behavior, as well as deconstructing a machista culture, however, they are still very recent.
\end{abstract}

\section{Keywords:}

Violence against women. Protective measures. Recidivism.

Recebido em: 9/5/2017

Aceito em: 14/2/2018

\section{Sumário:}

1 Introdução. 2 Violência Doméstica: A Aplicabilidade e Eficácia das Medidas Protetivas Como Instrumento de Prevenção e Combate à Reincidência na Comarca de Barra do Garças-MT. 2.1 Violência Doméstica: traços de lutas e poder. 2.2 Tipos de Violência Doméstica e Familiar Positivados Pela lei Maria da Penha (11.340/2006). 2.3 Lei Maria da Penha e Suas Medidas Protetivas de Urgência Contra a Violência Doméstica. 2.4 A Eficácia das Medidas Protetivas de Urgência. 2.5 Análise de Reincidência do Contexto Geral ao Contexto de Barra do Garças-MT. 3 Considerações Finais. 4 Referências. 


\section{INTRODUÇÃO}

Ao questionar os índices de violência doméstica contra a mulher no ambiente familiar no Brasil, verifica-se uma série de fatores culturais, históricos e religiosos que contribuíram ao longo da História para uma prática reiterada dessas açôes. Muitos movimentos populares feministas, no entanto, com o passar do tempo mudaram em diversos aspectos esse contexto de submissão e violência veladas.

Nesta perspectiva, a presente pesquisa analítica surge fundamentada em doutrina, dados científicos e pesquisa de campo com o intuito de percorrer caminhos que levem a esclarecer sobre a eficiência e aplicabilidade de leis especiais, na redução da violência contra a mulher e, assim, verificar os motivos que induzem ou que facilitam a prática da reincidência na Comarca de Barra do Garças-MT, situada no estado de Mato Grosso.

Para tanto foi necessário questionar: Até que ponto houve uma superação de velhas estruturas jurídicas que, historicamente, subjugaram as mulheres? Ou, ainda, qual a efetividade e aplicabilidade destas leis de enfrentamento da violência contra mulher em Barra do Garças/MT e até que ponto tais medidas inibem a reincidência? Surge, então, esta pesquisa que tem como tema: Violência Doméstica: A Aplicabilidade e Eficácia das Medidas Protetivas como instrumento de prevenção e combate à reincidência na Comarca de Barra do Garças-MT. Assim entendida, acredita-se que a referida análise poderá conduzir a reflexôes concretas sobre a situação e posição da mulher na sociedade nos dias atuais, avaliando o conflito entre a lei, a prática criminosa e o auxílio prestado a quem sofre esse tipo de violência.

Seguindo tal perspectiva, a pesquisa constitui-se em uma análise aplicada de cunho exploratório e abordagem quantiqualitativa. E para alicerçar este estudo buscou-se autores cujas obras fundamentam a referida discussão, como Cavalcante e Resende (2014), que fazem um estudo sobre a Lei Maria da Penha e a Rede de Enfrentamento em Barra do Garças - MT; Pacheco (2015), que traz um estudo sobre a ineficácia das medidas protetivas de urgência, e Cardoso (1997), que apresenta análise entre a Psicologia e as relaçóes de gênero na violência conjugal em relação às mulheres. 
Assim, o primeiro tópico desta análise traz uma contextualização histórico-sociológica em que, notadamente, buscou-se evidenciar a evoluçáo da figura feminina na sociedade, suas conquistas em vários setores ao longo da História mundial até a contemporaneidade, no intuito de facilitar um estudo de comportamentos da sociedade atual, principalmente daqueles que, ainda, se permitem pensar e agir como outrora.

Na sequência, o segundo item esclarece sobre os tipos de violência doméstica e familiar concebidos pela Lei Maria da Penha (11.340/2006), para que se tenha consciência de quando o ato é considerado lesivo. Em seguida, o próximo tópico traz as medidas protetivas de urgência, adotadas em defesa das vítimas, bem como contra os agressores para coibir tais atos e para que estes náo voltem a cometê-los. A quarta seção nasce com a intenção de tratar da eficácia das medidas apresentadas no item anterior. Verifica-se sua aplicabilidade e os motivos de náo se tornarem, de fato, eficazes. Prosseguindo, outro tópico é levantado, este embasado em dados obtidos pela pesquisa de campo para analisar a reincidência em Barra do Garças-MT e mais uma vez confronta a eficácia das medidas protetivas de urgência propostas pela Lei Maria da Penha, agora sob foco específico desta Comarca.

Por fim fundamenta-se tal análise, tendo partido do todo para uma base sintética em que se constata uma evoluçáo em termos de legislação em favor dos direitos da mulher, mas que há ainda muito caminho para percorrer no intento de proporcionar a ela uma vida digna, em que todos os direitos humanos também sejam garantidos e, em suma, respeitados.

\section{VIOLÊNCIA DOMÉSTICA:}

\section{A Aplicabilidade e Eficácia das Medidas Protetivas Como Instrumento de Prevenção e Combate à Reincidência na Comarca de Barra do Garças-MT}

\subsection{Violência Doméstica: Traços de Lutas ePoder}

A história da luta feminina é marcada por um passado de subordinação ao poder masculino, em que as funções delegadas à mulher eram somente a procriação, a manutenção do lar e a educação dos filhos. Passou por milênios 
de inferiorização, submissão e desqualificação, acorrentada culturalmente a concepçôes e demandas machistas, destinada a ser apêndice do homem, jamais seu semelhante.

Assim, confronta-se ao longo da História da humanidade com casos de violência intrafamiliar - tendo como foco a figura da mulher - que eram considerados normais, posto que a família surgiu submissa ao pátrio poder, que detinha todos os direitos sobre a vida dos filhos e esposa. Tal violência chegou a ser considerada banal e legal, a mulher tinha de suportar sem queixa; na Idade Média, por exemplo, o esposo poderia punir sua esposa para repelir um comportamento considerado por ele inadequado ou para reivindicar sua superioridade. Os atos eram considerados legais desde que não quebrassem ossos ou deixassem hematomas na face de sua companheira.

Apesar de algumas conquistas sociais femininas já terem sido alcançadas, somente no século 20 , por volta da década de 40 , o feminismo começa a mostrar esperança de um futuro diferente. Com o avanço científico e tecnológico, após as grandes guerras mundiais, e a necessidade de mão de obra barata, a mulher toma o lugar de assalariada e passa a conquistar, gradual e arduamente, direitos e garantias para a consolidação de igualdade entre os gêneros.

Mesmo com décadas de luta, a igualdade não atingiu os níveis aceitáveis e almejados pela população feminina, pois, ainda hoje, a mulher está exposta à violência e opressão, mantida por uma maioria machista, que é parte dominante da sociedade. Os índices de violência praticada contra elas são assustadores. Desse modo, mesmo administrando o cotidiano doméstico e buscando vagas no mercado de trabalho, elas ainda devem conquistar legitimidade e respeito social tanto em casa, para com o companheiro, quanto na sociedade em que estáo inseridas.

Salienta-se, portanto, entre as conquistas femininas, algumas que obtiveram grande sucesso e são responsáveis pela redução da violência contra a mulher no Brasil, tais como: o Plano Nacional para as Mulheres; a criação de Delegacias Especializadas para atendimento às mulheres (Delegacia Especial de Atenção à Mulher - Deam); criação da Lei 11.340/2006 - Lei Maria da Penha, que em 2016 
completou 10 anos de criação; Tipificação Penal para o Feminicídio, entre outros Grupos Sociais de Trabalho de Enfretamento da Violência Doméstica e Familiar, como a Rede de Frente (Barra do Garças - MT).

Segundo o site governamental "Compromisso e Atitude" inspirado na Lei Maria da Penha, o Brasil está em sétimo lugar no ranking mundial desse tipo de crime, uma vez que se contabiliza 4,4 assassinatos a cada 100 mil mulheres. Por essa razão faz-se imprescindível a criação de políticas públicas e ações sociais de combate à violência.

Os dados incham as estatísticas e mostram que tais agressóes não se trata de casos isolados. Como é possível observar, desde os primórdios da civilização humana fazem-se presentes e trazem uma combinação intrincada de fatores sociais, culturais, históricos, econômicos, em um contexto linear, no qual a mulher, apesar de muitas evoluçôes nas leis, no gênero e na atividade socioeconômica, ainda é posta em situação inferior.

Maria da Penha Maia poderia ser apenas mais um exemplo, entre muitas mulheres que padeceram deste mal no Brasil; no entanto peregrinou durante anos nos corredores de fóruns exigindo punição a seu cônjuge (que a agrediu por um período de seis anos, tendo atentado contra sua vida em duas oportunidades, e só foi condenado 19 anos após sua decisão de buscar justiça). Com isso, conseguiu bem mais que a punibilidade de seu agressor, pois o Brasil, que por muito tempo se permitiu ter elevados índices de violência doméstica sem demonstrar interesse em tipificá-la de forma efetiva, passou a ser pressionado por organizaçóes internacionais, ao saber do caso de Maria da Penha Maia e dos índices desse tipo de violência no país. Assim surgiu a Lei 11.340/2006, com aparo e impulso da Organização dos Estados Americanos (OEA), que "sugeriu" ao Estado brasileiro legislaçóes que condenassem tais atos criminosos com o intuito de que se consolidasse de vez a materialidade dos direitos humanos inerentes a todas as mulheres e a todo ser humano.

A Lei Maria da Penha (11.340/2006), com 12 anos de vigência, advém dessas várias lutas (não só de Maria da Penha Maia), de movimentos de enfrentamento à violência contra a mulher no âmbito doméstico e familiar; prevê medidas protetivas 
de urgência para evitar o contato com o agressor, ou seja, o Estado passa a garantir direitos e proteção com a aplicação da lei contra hábitos e valores de uma sociedade ainda machista e retrógrada.

É inegável que na contemporaneidade ainda se vive os resquícios deste rastro de cultura de submissão, no entanto muito se caminhou em termos de legislação, a qual coíbe qualquer tipo de violência contra a mulher.

\subsection{Tipos De Violência Doméstica E Familiar Positivados Pela Lei Maria Da Penha (11.340/2006)}

A mencionada violência doméstica e familiar em desfavor da figura da mulher ainda é pouco debatida pela doutrina e jurisprudência. Sabemos que se trata de uma problemática antiga, como já abordado, e, por isso, estava envolta por tradiçôes que doutrinadores e aplicadores do Direito não se viam com competência para interferir. A Lei Maria da Penha surgiu após muita influência internacional, tentando solucionar o problema aplicando medidas protetivas às mulheres vítimas dos tipos de violência elencados no artigo $7^{\circ}$ da supracitada lei:

Art. 7o São formas de violência doméstica e familiar contra a mulher, entre outras:

I - a violência física, entendida como qualquer conduta que ofenda sua integridade ou saúde corporal;

II - a violência psicológica, entendida como qualquer conduta que lhe cause dano emocional e diminuição da autoestima ou que lhe prejudique e perturbe o pleno desenvolvimento ou que vise degradar ou controlar suas açóes, comportamentos, crenças e decisões, mediante ameaça, constrangimento, humilhação, manipulação, isolamento, vigilância constante... (BRASIL, 2006)

A violência física tem como objetivo ferir o corpo da vítima: é o tapa, o soco, a queimadura. É encarada, por muitos estudiosos, como o resultado final de uma série de violaçóes, como a violência psicológica, que se apresenta de forma não tão brusca, por meio de xingamentos, proibiçóes e toma proporçôes gigantescas. 
Sobre violência psicológica, Hugo Leonardo de Souza e Latif Antônia Cassab, em seu texto Feridas que náo se curam: a violência psicológica cometida à mulher pelo companheiro, observam:

\begin{abstract}
Muitas pessoas nem sequer conhecem as expressôes da violência psicológica. Tal condição é resultado da ideologia romântica que possuem sobre família, ou seja, a família deve viver em harmonia e, os que não se enquadram a esse padrão são considerados "desestruturados". Na efetivação da harmonia familiar, muitas vezes, há um processo de naturalização da ofensa verbal, ou seja, para muitos homens "é normal" ofender verbalmente a mulher, tratando-a como propriedade, concebendo, através de uma perspectiva confessional, que foi para isso que ele foi criado, para ser o mantenedor da família e, consequentemente, o "dono" da mesma (SOUZA; CASSAB, 2010).
\end{abstract}

Infelizmente essa forma de violência é muito comum e, muitas vezes, não é considerada violação pela própria vítima, portanto a demora em procurar ajuda acaba culminando em violência física. $\mathrm{O}$ agressor, valendo-se da condição privilegiada da relação de confiança ou intimidade que tem ou que tenha tido com a vítima, bem como da relação de hierarquia que detenha, passa a agredi-la de todas as maneiras.

\title{
2.3 Lei Maria da Penha e Suas Medidas Protetivas de Urgência Contra a Violência Doméstica
}

Os casos de violência doméstica, antes da Lei Maria da Penha, eram considerados crimes de menor potencial ofensivo, estabelecidos na lei 9.099/95. Assim, as penas eram irrisórias e variavam entre pagamento de cestas básicas e prestação de serviços à comunidade, o que justificava os elevados índices constatados. O texto da Lei aqui analisada trouxe mudanças que a colocaram entre as melhores leis que tratam sobre violência contra mulher no mundo; aumentaram-se as sançôes a quem agride e também as medidas que visam a proteger a vítima.

Assim, a fim de que se tenha uma base teórica para avaliar a eficácia ou inexistência dela nas medidas protetivas de urgência, que a lei Maria da Penha traz, passa-se aqui, então, à fase de cognição para o conhecimento de cada uma destas medidas e a seguir um estudo analítico quanto a sua efetividade. Após a instituição 
da Lei 11.340/2006 o Estado passou a conter atos de violação doméstica mediante um conjunto de açôes articuladas entre Uniâo, Estados, Distrito Federal e municípios, como disposto no artigo $8^{\circ}$ desta mesma Lei:

Art. $8^{\circ} \mathrm{A}$ política pública que visa coibir a violência doméstica e familiar contra a mulher far-se-á por meio de um conjunto articulado de açóes da União, dos Estados, do Distrito Federal e dos Municípios e de ações não governamentais, tendo por diretrizes:

I - a integração operacional do Poder Judiciário, do Ministério Público e da Defensoria Pública com as áreas de segurança pública, assistência social, saúde, educação, trabalho e habitação; (...)

IV - a implementação de atendimento policial especializado para as mulheres, em particular nas Delegacias de Atendimento à Mulher (BRASIL, 2006).

As medidas protetivas de urgência vêm dispostas no capítulo II da Lei 11.340/2006, entre os artigos 18 e 24, divididas em disposiçóes gerais, seção I, que determinam prazos e maneiras de impetrá-las, e seção II, das garantias à ofendida as que obrigam o agressor a uma série de medidas. O Estado, entáo, busca prevenir qualquer açáo violenta do agressor, antes de ocorrer o ato e durante o caminhar do processo (caso em que já tenha cometido agressão), assim como garantir à vítima uma tutela jurisdicional que pode ser requerida em qualquer fase deste processo.

Desse modo, para que o juiz conceda medidas protetivas de urgência à vítima, estas deverão ser requeridas pelo Ministério Público ou pela própria ofendida. Tais medidas podem ser disponibilizadas imediatamente, decretadas por um juiz. A efetivação não dependerá de audiência entre as partes; sempre que a integridade da ofendida for ameaçada, o delegado deverá encaminhar em até 48 horas o expediente referente ao pedido, após a denúncia da ofendida. $\mathrm{O}$ juiz ainda poderá, a requerimento do Ministério Público, rever estas medidas ou reforçá-las visando à efetivação desta proteção. Cavalcante e Resende, no artigo A lei Maria da Penha e a rede de enfrentamento à violência contra a mulher no município de Barra do Garças-MT, discorrem:

Para concessão de medidas protetivas há a necessidade da presença da semelhança entre os depoimentos da ofendida e demais testemunhas, e que deve ser reconhecido o fumus bonis iuris, que é a fumaça do bom direito, ou seja, 
o magistrado reconhece que a vítima possui direito de requerer a concessão de medidas protetivas, para assegurar sua integridade. $\mathrm{O}$ periculum in mora é traduzido com o significado do perigo da demora, pois, se houver atraso no deferimento das medidas cautelares, a ofendida pode ser lesionada (CAVALCANTE; RESENDE, 2014).

Inicialmente vem a fase das oitivas. Ouvem-se vítima e testemunhas para averiguar a veracidade dos fatos narrados, porém o Estado tem urgência na liberação das medidas, por reconhecer e resguardar o bem juridicamente tutelado, ou seja, a integridade física da pessoa agredida. Então, o Boletim de Ocorrência é lavrado para registrar a ação da ofendida em provocar o sistema jurisdicional a protegê-la, física e psicologicamente e, logo após, deve decidir quanto à representação criminal contra seu agressor. $\mathrm{O}$ artigo 20 da referida Lei determina que o agressor poderá ter prisão preventiva decretada pelo juiz em qualquer fase do Inquérito Policial ou Instrução Criminal. Isso se dá por meio de um ato de ofício do Juiz ou a requerimento do Ministério Público ou, ainda, por meio de representaçáo de autoridade policial. Ao juiz, também, é facultado decretar ou revogar a prisáo conforme a necessidade subsista e a prejudicada deverá ser comunicada de todos os atos relativos à prisão ou soltura do agressor.

$\mathrm{O}$ artigo 22 dispóe sobre medidas que obrigam o agressor. Entre elas prevê como imprescindível o afastamento do agressor do convívio com a vítima, fixa um limite mínimo de distância entre a ofendida e o agressor, para que as medidas alcancem eficácia, assim como é vedado qualquer meio de comunicação entre seus familiares e testemunhas. A lei também dispóe sobre a suspensão ou restrição ao porte de arma de fogo. Tais medidas poderão ser aplicadas isoladas ou cumulativamente, conforme a gravidade do caso.

Na cidade de Barra do Garças-MT, segundo Cavalcante e Resende (2014), para a efetiva aplicação de tais medidas ainda fica estabelecido que o agressor compareça ao Centro de Referência Especializado de Assistência Social - Creas - onde será submetido à avaliação, acompanhamento e frequência à Rede de Enfrentamento Contra a Violência Doméstica. Essas medidas são de cunho preventivo objetivando, também, a não reincidência nos crimes decorrentes de relação íntima de afeto. Para coibir o descumprimento dessas medidas a Lei Maria da Penha determina no 
artigo 42 a prisão preventiva, recepcionada pelo Código de Processo Penal, em seu artigo 313, positivados como um crime de desobediência, assegurando garantias de proteção à vítima.

Art. 313. Nos termos do art. 312 deste Código, será admitida a decretação da prisão preventiva:

III - se o crime envolver violência doméstica e familiar contra a mulher, criança, adolescente, idoso, enfermo ou pessoa com deficiência, para garantir a execução das medidas protetivas de urgência (BRASIL, 1941).

Em garantia à ordem pública, em conveniência à instrução criminal e assegurando a aplicação da lei, a prisão preventiva deve ser decretada pelo juiz de ofício, a requerimento da vítima ou do Ministério Público.

\subsection{A Eficácia das Medidas Protetivas de Urgência}

Durante o período de um ano de pesquisa constatou-se que no município de Barra do Garças-MT há elevada incidência de crimes domésticos e familiares contra a mulher. $\mathrm{O}$ contato com inquéritos durante a fase de tabulação de dados para esta pesquisa trouxe noçóes mais objetivas da dimensão do mal que assola esse grupo social e, dessa forma, fez surgir questionamentos sobre a eficácia das medidas protetivas de urgência. Neste contexto, tendo a Lei Maria da Penha 12 anos de efetivação, Cavalcante e Resende argumentam que:

Todas as ações penais relacionadas a essa violência têm como Vara competente para julgamentos o Juízo da 2a Vara Criminal. Em entrevista com o Dr. Wagner

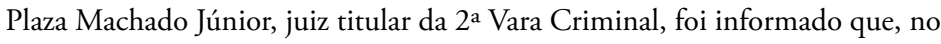
início de 2013, ano em que foi designado para a referida Vara, ele se deparou com julgamentos pendentes desde o ano de 2008. A sua preocupação se deu pelo fato de as vítimas de violência doméstica buscarem amparo do Estado, para que possam cumprir com o seu dever de sancionar o agressor, mas a vítima se sente fragilizada em não obter resposta do Estado-Juiz, pela demora na tramitação do processo, o que gera a impunidade (CAVALCANTE; RESENDE, 2014). 
Um dos fatores questionados que contribui para a ineficácia das medidas protetivas decorre do fato de que a Lei Maria da Penha náo criou tipos penais, apenas se reporta aos crimes já previstos no Código Penal, e este aplica penas relativamente pequenas e com prazo prescricional curto. Os agressores, na maioria das vezes, cumprem as penas em regime penal aberto e com a assinatura mensal de uma ficha de comparecimento em juízo. Essa ausência de penas mais contundentes contribui, diretamente, para o grande número de repetiçóes dos casos destes crimes pelos mesmos agressores, contra as mesmas vítimas. É a concretização da reincidência. Observando isto, foi criada no município uma rede de acompanhamento psicológico para agressores e vítimas, com o intuito de reverter os índices de reincidência.

Tratar de eficácia dessas medidas, porém, não se satisfaz com tais ponderaçôes, exige um minucioso estudo, sabendo-se que tal violência não é visível ao pleno diagnóstico, tanto para a sociedade quanto para o Estado, que zela pela proteção às vítimas deste mal, pois muitos casos sequer chegam a ser denunciados. Há vários tipos de violência contra mulher - psicológica, física - e esta, no exercício de seu livre-arbítrio, opta pela "pseudo" proteção do lar e dos filhos em detrimento de seu próprio sofrimento.

Tal violência é silenciosa, pois tem origem no lar, no seio familiar em que pais, cônjuges, filhos, se impóem por meio de atos lesivos como forma de legitimação de um poder que independe de classe social, crença, etnia e que, muitas vezes, por colocar este "lar" em primeiro lugar, estas mulheres preferem se calar. Pensando nestes fatores elencados, faz-se necessário indagar se é possível calcular a real eficácia das medidas positivadas e adotadas, uma vez que, nessa perspectiva, não haveria como contabilizar dados precisos dessas agressóes e/ou repetiçóes. Infelizmente tal fato também é resultado da falta de confiança que a vítima deposita nos meios de proteção. Muitas temem que a situação piore, pois são ameaçadas e o fato de esse agressor continuar em liberdade, mesmo com medidas de segurança, não garante que ele não descumpra e reincida, pois as autoridades policiais não têm efetivo suficiente para monitoramento de 24 horas dessas vítimas.

A pesquisa do Data Senado revelou as diferentes razóes que impedem a mulher de recorrer à Lei para enfrentar seus agressores. A principal delas é o "medo do agressor", na percepçáo de $78 \%$ das entrevistadas em pergunta de múltipla escolha. O dado é revelador porque o medo se sobressai expressivamente em 
relação às demais razões. As outras opçóes - "vergonha", "não garantir o próprio sustento" e "punição branda" - atingiram percentuais abaixo de 10\%. Outros motivos foram citados por $16 \%$ das mulheres. A análise desses dados não deixa dúvida de que o medo é o principal obstáculo na luta contra a violência doméstica e familiar (DATA SENADO, 2009 apud PACHECO, 2015).

O medo solidifica relaçóes de domínio, de subjugação e, como já mencionado, não deixa que o Estado tenha conhecimento, evidenciando que, para que a vítima tome coragem e denuncie a agressão, há que haver maior efetividade destas medidas, pois afastar o agressor apenas com uma determinação judicial, como é constatado, não as torna eficazes. Não há fiscalização para averiguar a efetividade de tais medidas e, muitas vezes, por meio de ameaças, o agressor obriga que a vítima faça retratação da representação para que a medida seja revogada. Desse modo, impera mais uma vez o medo e o silêncio, e este silêncio das vítimas torna impossível a solução dos casos, prolongando o sofrimento, em algumas situaçóes, para o resto de seus dias. Não é válido, no entanto, afirmar que todos os casos de descumprimento das medidas acontecem em decorrência de sua falta de efetividade ou negligência do Estado. Pacheco, em seu estudo sobre a (In)eficácia das Medidas Protetivas de Urgência, observa que:

As Medidas Protetivas estabelecidas pelo juiz muitas vezes tomam um curso diferente do esperado, pois são ineficazes para solucionar os problemas emergentes nos casos. Acontece que na maioria das vezes o problema está na própria vitima quando resolve se retratar e reatar com o agressor, com isso torna as medidas sem eficácia alguma. Nem sempre é o Judiciário o responsável pela não eficácia das medidas, isso porque quando a própria vitima resolve por bem se retratar da representaçáo consequentemente as medidas de proteção são revogadas pela autoridade que estabeleceu, no caso o Juiz (PACHECO, 2015).

Relevante ressaltar que, de acordo com decisão do STF, essa retratação atualmente deve ser feita perante o juiz, em audiência específica para esta finalidade e antes que a denúncia seja recebida em juízo, pois, após esse fato, mesmo que a vítima queira reatar com o agressor e vier pedir retrataçáo, o processo prosseguirá normalmente e as medidas protetivas que foram decretadas não serão revogadas. Isso porque a ação passa a ser incondicionada à representação da vítima, devido aos 
inúmeros casos de reincidência de violência doméstica em que as vítimas teriam retirado sua queixa. Este é mais um dispositivo importante no combate à reiteração das práticas delitivas em desfavor da mulher, porém ainda existem números expressivos que merecem cuidados, políticas públicas condizentes às necessidades das vítimas e tratamento destes agressores.

\subsection{Análise de Reincidência do Contexto Geral ao Contexto de Barra do Garças-MT}

O caminho para dominação é lento, ninguém começa uma relação batendo; o agressor ganha espaço na vida da vítima, ganha a confiança, seu respeito, afeto e, assim, constroem uma relação familiar. Este mesmo ser que demonstrou cuidado, porém, não se permite viver sob a igualdade de gêneros, pois de alguma maneira o mundo o fez acreditar não ser possível à figura de uma mulher tomar posto de igualdade ao seu, e a partir daí, surgem discórdias, ofensas verbais, e logo, um empurrão, depois um tapa, mais tarde todo tipo de sadismo. A pessoa que a cativou e na qual depositou toda a confiança a deixa com hematomas em todo corpo.

Para a autora Marie-France Hirigoyen, tais atos de violência física podem acontecer apenas uma vez como, também, podem se tornar repetitivos. Segundo ela, o que garante uma escala de intensidade e frequência é a denúncia destes atos. Para a autora, a primeira agressão vem antes dos tapas, ocorre por meio de violência psicológicas - ameaças, gestos, palavras, proibição de usar determinada roupa, fazer determinada coisa, sair com amigos, situaçóes que progridem paulatinamente e que sáo facilmente esquecidas com um pequeno gesto de carinho e que, por este motivo, se repetem.

Para que a violência possa perdurar é preciso isolar progressivamente a mulher de sua família, de seus amigos, impedi-la de trabalhar, de ter uma vida social. Isolando sua mulher, o homem faz com que sua vida fique voltada unicamente para si. Ele precisa que ela se ocupe dele, que só pense nele. Age de modo a que ela não seja demasiadamente independente, para que não escape a seu controle. As mulheres dizem muitas vezes que se sentem prisioneiras (HIRIGOYEN, 2006). 
O isolamento da vítima pelo agressor passa a ser conveniente, uma vez que assim esta mulher fica restringida ao seu poder, não tendo a quem recorrer quando agredida. Então, a mulher passa a acreditar que todo o martírio vivido é justificável, que é normal na vida de um casal, para o bem e conservação da instituição familiar. E essa tentativa de conservar a relação conjugal a todo custo faz com que coloque em risco a própria vida. Cardoso sobre isso argumenta:

A mulher tem necessidade de manter a relaçáo, nem que para isso tenha de assumir a responsabilidade de tudo que ocorre no relacionamento. Isso está associado à socialização feminina tradicional, a qual coloca que, para a mulher ser considerada completa, deve ter um companheiro permanente. Insistir num relacionamento após sucessivos episódios de violência ou retornar à relaçáo após a separação é constante na vida das mulheres que sofrem violência conjugal (BIAGI, 2014 apud CARDOSO, 1997).

Infelizmente, mesmo nos dias atuais não é raro encontrarmos mulheres que se abastecem desse tipo de pensamento e acreditam terem feito a melhor escolha. $\mathrm{O}$ ciclo de agressão, segundo Biagi, não decorre somente da opção dessas mulheres em não denunciar seu agressor ou habituarem-se às agressóes. Para a autora, existe um fator ainda invisível ao Estado que impede o registro das ocorrências, as ameaças que não estão visíveis, veladas, fazendo com que vivam, cronicamente, intimidadas.

Muitas vezes essas mulheres buscam amparo jurídico sem receber uma proteção eficaz, que resolva em definitivo a situação vivenciada e as medidas tornam-se insuficientes. Faz-se relevante expor, ainda, que mesmo após o Estado ter interposto o amparo das medidas protetivas à vítima e este agressor vier a desobedecer tal medida, vindo a agredi-la novamente, para que o Estado tome novas providências a prejudicada terá de comparecer até uma delegacia e fazer novos registros desta agressão, pois não existem meios de monitoramento de todos os possíveis casos. Além de que, o descumprimento da medida na maior parte das situaçóes virá acompanhado de outras violaçóes, fazendo, assim, com que estas mulheres, com medo, escolham o silêncio.

Desse modo, com o objetivo de verificar os casos de desobediência das medidas protetivas e, assim, tomar conhecimento dos níveis de reincidência, foram analisados dados colhidos entre os anos de 2013 e 2015 - especificamente até julho 
de 2015 - referentes às ocorrências de violência doméstica e familiar registrados na Comarca de Barra do Garças-MT; totalizando 801 inquéritos policiais. Este número é relativamente alto quando se pensa que a Comarca de Barra do Garças-MT abarca, além da referida cidade (que possui 58.690 habitantes, segundo previsão do IBGE/2016), os municípios de: Araguaiana (3.059 habitantes), Pontal do Araguaia (6.259 habitantes), General Carneiro (5.286 habitantes), Torixoréu (3.644 habitantes) e seus respectivos distritos.

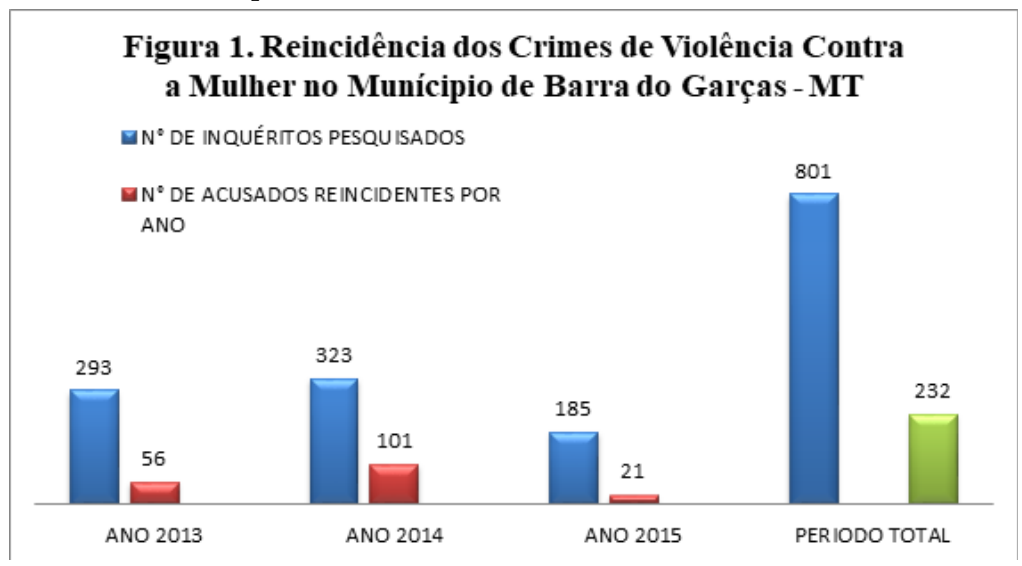

Percebe-se neste estudo que um número considerável de casos de reincidência de violência doméstica e familiar contra a mulher na Comarca mencionada, ainda exibe vultosa soma, mesmo com a aplicação das medidas de proteção. Isso faz com que, mais uma vez, se questione sua eficácia.

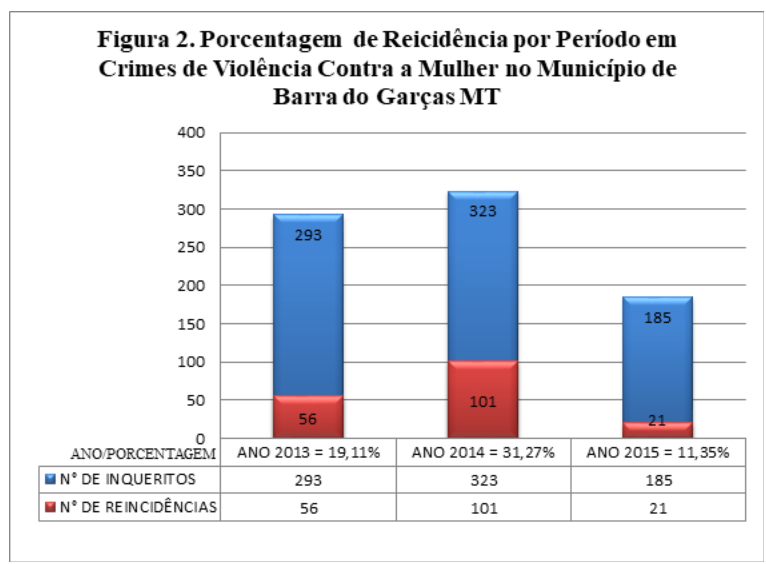


Em 2013 foram analisados 293 inquéritos referentes a este tipo de violação, e destes casos, 19,11\% voltaram a cometer novas agressóes contra as mesmas vítimas. Nos anos posteriores estes números de reincidência elevaram-se: em 2014 somam-se 323 inquéritos, com 31,27\% de repetição dos casos. Já no ano seguinte, com apenas seis meses analisados, tem-se $11,35 \%$ de casos de reincidência. Isso leva a concluir que as medidas protetivas de urgência e todos os seus mecanismos de defesa e proteção à mulher têm falhado.

Há que destacar que a Lei Maria da Penha ainda é muito recente, assim como, obviamente, todas as medidas protetivas nela previstas, citando-se aqui o projeto de política pública na Comarca analisada: a Rede de Enfrentamento à Violência Contra Mulher (que busca minimizar essa situação de violência reincidente na Comarca de Barra do Garças-MT), que teve sua instituição em setembro de 2013.

\begin{abstract}
A Rede de Enfretamento à Violência Contra a Mulher, em Barra do Garças, tem por escopo articular as instituiçóes e serviços para o desenvolvimento de mecanismos efetivos de cautelas e de artifícios, que garantam o fortalecimento das mulheres e de seus direitos, a responsabilizaçáo dos autores de violência e a assistência qualificada às mulheres em situação de violência, o que caracteriza uma política pública para reduzir o índice de violência doméstica existente na Comarca (CAVALCANTE; RESENDE, 2014).
\end{abstract}

Tal Rede de Enfrentamento vem desenvolvendo um árduo trabalho de acompanhamento de vítimas e agressores. Sediada no Centro de Referência Especializado de Assistência Social (Creas), recebe, então, vítimas de violência doméstica para um acompanhamento psicossocial, quando elas tomam a decisão em fazê-lo. Assiste, também, os agressores, todavia o acompanhamento para estes faz parte de uma medida protetiva determinada pelo juiz, entendendo o magistrado que ao agressor não deve, apenas, ser imputadas penas punitivas, mas, também, aquelas de caráter pedagógico, para que o faça pensar em suas açôes, sobre a violência desferida e sobre suas impressóes impregnadas de cultura machista. São, nestas reunióes, disponibilizadas palestras semanais com assistentes sociais, médicos, psicólogos, professores, que abordam temas que os façam refletir e questionar suas atitudes. Cavalcante e Resende destacam que: 
Tem função restaurativa, que vai além do tratamento dado pela justiça comum, uma vez que a aplicação de penas náo é eficaz, tenta restaurar e influenciar o comportamento do agressor, para que náo volte a reincidir nos delitos da seara doméstica, fazendo-o perceber que suas atitudes não se adequam aos novos parâmetros sociais (2014).

Desse modo, a partir dessas açôes sociais da Rede de Enfrentamento, pode-se constatar que o aumento do número de inquéritos tornou-se positivo, à medida que se percebe que as vítimas vão à procura de ajuda, situação antes inimaginável por muitas delas. Se hoje o fazem é pelo fato de confiarem mais na lei, no sistema jurídico, destacando-se que a Rede de Enfrentamento tem investido em palestras em escolas, intuindo que a divulgaçáo das medidas protetivas seja um meio para inibir tais atos de violência e até de incentivar mulheres que ainda sofrem caladas a tomarem posse de seus direitos, de terem seu corpo e saúde resguardados e protegidos, inclusive, daqueles com quem convive.

Sabe-se que as medidas protetivas de urgência, como discutidas no corpo deste texto, ainda não são efetivas na totalidade, uma vez que existem muitos casos de reincidência, ressaltando-se que muitos dos casos analisados evidenciam agressores que voltam a cometer as violências com intervalo de um ano, ou as cometem, repetidamente, durante todos os anos analisados.

Há que se elaborar políticas públicas mais contundentes, de forma a dar concretude ao que já se tem conquistado, para que, futuramente, se possa imaginar uma sociedade verdadeiramente igualitária, em que se respeitem, na íntegra, os fundamentos constitucionais dos direitos humanos. Homem e mulher tendo, de fato, os mesmos direitos e deveres, sem que haja relaçóes abusivas por nenhumas das partes nessa relação intrafamiliar.

\section{CONSIDERAÇÕES FINAIS}

É notório que a Lei Maria da Penha trouxe um enorme progresso social, entretanto há um extenso caminho a ser percorrido para que, de fato, a violência contra a mulher seja erradicada. Sabe-se que a violência deixa um legado intenso de cicatrizes e marcas nas mulheres, além de desestruturar a instituição familiar, 
gerando um padrão repetitivo desse tipo de violência, no sentido de que a violência intrafamiliar vivida por crianças, durante sua infância, influencia diretamente nos padrôes familiares futuros, na medida em que recria o modelo de pai vivenciado no exercício de sua paternidade.

Embora os avanços jurídicos e socioculturais que a mulher conquistou sejam evidentes, como a Lei Maria da Penha, ainda se vive sob resquícios de um modelo machista baseado no poder pátrio, em que homens utilizam de violência psicológica ou física para se impor ou colocarem a mulher em papel de submissão.

Deste modo, tornou-se relevante verificar a aplicabilidade e eficácia das medidas protetivas de urgência como instrumento de prevenção e combate à reincidência, especificamente na cidade de Barra do Garças-MT. Nesse sentido, com base em dados colhidos de inquéritos policiais entre os anos de 2013 e 2015 sobre este tipo de violação, constatou-se os altos índices de violência doméstica e familiar contra a mulher existentes na cidade pesquisada, assim como números precisos das repetiçóes desses atos violentos desferidos pelos mesmos autores às mesmas vítimas, ou seja, a reincidência.

A partir de então, com base na proposta das medidas protetivas de urgência positivadas e descritas pela Lei Maria da Penha e sua aplicabilidade na cidade de Barra do Garças-MT, investigou-se sua real eficácia. Concluiu-se que tais açóes ainda se mostram insuficientes para prevenir e combater a reincidência da violência contra as mulheres. Mesmo amparadas, muitas mulheres voltam a ser agredidas pelos mesmos algozes de antes, tendo alguns destes agressores reincidido em todos os anos aqui pesquisados.

Programas sociais como a Rede de Enfrentamento Contra a Violência Doméstica (uma medida de proteçâo criada com o intuito de diminuir tais casos de reincidência de violência doméstica contra a mulher) oferecem novos caminhos que podem auxiliar na mudança de comportamento do agressor, bem como desconstruir uma cultura machista vivenciada desde a infância, pois colocam também como foco o tratamento do agressor e náo apenas o acolhimento das vítimas.

O programa ainda é recente, porém reafirma-se a importância do trabalho que tem desenvolvido. Como base nestas açóes, futuramente, imagina-se que possam ser apresentados números mais satisfatórios e encorajadores do que hoje 
é encontrado, no que se refere ao número de reincidências, ainda elevado. $\mathrm{O}$ significativo índice de violência computado se dá, antes de tudo, pelo fato de estas mulheres violentadas optarem pela denúncia ao invés do silêncio, e isso é resultado do trabalho de conscientização desenvolvido pela Rede de Enfrentamento à sociedade barra-garcense, a qual esclarece as garantias dispostas pela Lei Maria da Penha, consequentemente as medidas de proteção por meio de palestras em escolas e atendimento individualizado dessas mulheres.

Desse modo, conclui-se que as leis, ainda, são muito brandas quando se trata da punibilidade da violência doméstica e intrafamiliar no Brasil e o descumprimento das penas são causas que potencializam a ocorrência da reincidência. Programas sociais como a Rede de Enfrentamento à Violência Doméstica em Barra do Garças-MT, têm trabalhado para reduzir os índices negativos, porém são açôes que necessitam de parceria de toda a sociedade para que os resultados das contínuas campanhas se efetivem. Dessa maneira, há que assegurar a responsabilização dos agressores (efeito punitivo), além de continuar fornecendo amparo psicológico qualificado para que não voltem a reincidir (efeito pedagógico).

\section{REFERÊNCIAS}

ANGELIM, Fábio Pereira. O pessoal torna-se político: o papel do Estado no monitoramento da violência contra mulher. Psicologia Política, vol. 9, n. 18, p. 259-274, jul./dez. 2009.

BIAGI, Sandra Fernandes. Lei Maria da Penha: a aplicabilidade das medidas protetivas de urgência como instrumento de prevençáo e combate à reincidência. Brasília, 2014. Disponível em: <http://bdm.unb.br/bitstream/10483/13099/1/2014_SandraFernandesBiagi. pdf $>$. Acesso em: 30 ago. 2016.

BRASIL. Lei Maria da Penha. Lei no 11.340/2006. Coíbe a violência doméstica e familiar contra a mulher. Brasília: Secretaria Especial de Políticas para Mulheres; Presidência da República, 2006.

. Política Nacional de Enfrentamento à Violência Contra as Mulheres. Brasília: Secretaria Especial de Políticas Para as Mulheres; Presidência da República, 2013. Disponível em<HTTP://www.spm.gov.br> Acesso em 21 de Agosto de 2016

. Convenção Interamericana para Prevenir, Punir e Erradicar a Violência contra a Mulher. Convenção de Belém do Pará, 1994.

. Constituição da República Federativa do Brasil. Brasília, DF: Senado, 1988. 
BRASIL. Código de Processo Penal. DOU República Federativa do Brasil: Poder Legislativo, Brasília, DF. 1941. Disponível em: <http://www.planalto.gov.br/ccivil_03/leis/decreto-lei/ del3689Compilado.htm > Acesso em: 25 ago. 2016a.

. Código Penal. DOU República Federativa do Brasil: Poder Legislativo, Brasília, DF. Disponível em: <http://www.planalto.gov.br/ccivil_03/decreto-lei/Del2848compilado. htm> Acesso em: 11 ago. 2016b.

CARDOSO, N. M. B. Psicologia e relaçóes de gênero: a socialização do gênero suas implicaçôes na violência conjugal em relação às mulheres. In: ZANELLA, A. et al. (Org.). Psicologia e práticas sociais. 19. ed. Porto Alegre: Abrasposul, 1997.

CAVALCANTE, Caio César Claudino; RESENDE, Gisele Silva Lira de Resende. A lei Maria da Penha e a Rede de Enfrentamento à Violência Contra a Mulher no município de Barra do Garças-MT. In: Facisa-On-line, vol. 3, n. 3, 2014.

COMPROMISSO E ATITUDE LEI MARIA DA PENHA. Dados e estatísticas sobre violência contra as mulheres. Disponível em: <http://www.compromissoeatitude.org.br/legislacao-sobre-violencia-contra-as-mulheres-no-brasil/>. Acesso em: 19 ago. 2016.

HIRIGOYEN, Marie-France. A violência no casal: da coação psicológica à agressão física. Trad. Maria Helena Kühner. Rio de Janeiro: Bertrand Brasil, 2006.

INSTITUTO BRASILEIRO DE GEOGRAFIA E ESTATÍSTICA (IBGE). Disponível em: <http://www.ibge.gov.br>. Acesso em: 30 set. 2016.

OLIVEIRA, Elisa Rezende. Violência doméstica e familiar contra a mulher: um cenário de subjugação do gênero feminino. Revista do Laboratório de Estudos da Violência da Unesp, Marília, 9. ed., maio 2012. Disponível em: <http://www2.marilia.unesp.br/revistas/index. php/levs/article/view/2283/1880. Acesso em: set. 2016.

PACHECO, Indiara Cavalcante. A (in) eficácia das medidas protetivas de urgência Lei Maria da Penha. 2015. Disponível em: <http://www.conteudojuridico.com.br/artigo,a-ineficacia-das-medidas-protetivas-de-urgencia-lei-maria-da-penha,53427.html>. Acesso em: 30 ago. 2016. POUGY, Lilia Guimarães. Desafios políticos em tempos de Lei Maria da Penha. Rev. Katál., Florianópolis, v. 13, n. 1, p. 76-85, jan./jun. 2010.

SOUZA, Hugo Leonardo; CASSAB, Latif Antônia. Feridas que não se curam: a violência psicológica cometida à mulher pelo companheiro. SIMPÓSIO SOBRE ESTUDOS DE GÊNERO E POLÍTICAS PÚBLICAS, 1., 2010. Anais... UEL, 2010. ISSN 2177-8248. Disponível em: <http://www.uel.br>gpp>>. 5.HugoLeonardo.pdf>. Acesso em: 30 ago. 2016. 